\title{
Some Clinics Are More Equal than Others
}

In January the Centers for Medicare and Medicaid (CMS) site-neutral policy went into effect (1). Under this policy payments to some off-campus hospital clinics were reduced to those of private practice physicians. However, Judge Rosemary M. Collyer said in her decision, "The Court finds that CMS exceeded its statutory authority when it cut the payment rate for clinic services at off-campus provider-based clinics". According to her decision, in the Bipartisan Budget Act of 2015 Congress allowed hospitals to bill CMS at the higher outpatient department rate if they existed prior to Nov. 2, 2015.

This is how hospitals gamed the system. Hospitals acquire a doctor's office or an emergency care clinic; hire salaried doctors to staff it; and raise the charges to what CMS would allow. They were able to do this because the doctor or practice was "grandfathered" and the fees are often 2-6 times the reimbursement for private physicians' offices (2).

This ruling is consistent with a long-standing trend in Congress to restrict free market forces in healthcare. Congress has "squeezed" physicians to an extent that most have little choice but to work for hospitals. There has been a meteoric growth in hospitalemployed physicians and hospital-owned physician practices. From July 2012 to July 2015 , the number of hospital-employed physicians increased $49 \%$ (3). The number of hospital-owned physician practices increased by 31,000 , which amounted to an $86 \%$ growth. Today more physicians are employed by hospitals than are in independent practices.

Also consistent with Congressional action to restrict free market forces has been its drug payment policy. CMS is forbidden from negotiating drug prices and is essentially forced to pay the price set by the pharmaceutical manufacturer. Private insurance companies follow CMS' lead and pass these increased costs to the consumer.

Several bills have been introduced in Congress to curb drug pricing. The Congressional Budget Office has repeatedly stated that in order to decrease drug prices it is necessary to allow the federal government to negotiate prices (4). However, this is apparently a "socialist" act according to Senate Majority Leader, Mitch McConnell. McConnell has long been a supporter of the pharmaceutical companies and hospitals by doing nothing to alter the present system, and thus allowing hospitals and pharmaceutical companies to avoid free market forces, fix prices, and ensure maximal profits.

The Trump administration's site neutral policy and allowing HHS to negotiate with pharmaceutical manufacturers are good policies that would likely lower healthcare costs and benefit patients. They are not "socialist" but instead attempt to restore to healthcare a free market economy that has long been missing. In George Orwell's "Animal Farm" the pigs control the government and proclaim that "All animals are equal, but some animals are more equal than others". The politicians who support inequitable 
reimbursement for the same healthcare service or allow pharmaceutical companies to overcharge for a drug are saying much the same.

Richard A. Robbins, MD

Editor, SWJPCC

\section{References}

1. Robbins RA. Court overturns CMS' site-neutral payment policy. Southwest J Pulm Crit Care. 2019;19(3):101-2. [CrossRef]

2. Carey MJ. Facility fees: the farce everyone pays for. Medical Economics. August 16, 2018. Available at: https://www.medicaleconomics.com/blog/facility-fees-farceeveryone-pays (accessed 9/19/19).

3. Cheney C. Hospital-physician consolidation growth trends moderate. Health Leaders February 28, 2019. Available at: https://www.healthleadersmedia.com/clinicalcare/hospital-physician-consolidation-growth-trends-moderate (accessed 9/21/19).

4. Cubanski J, Neuman T, True S, Freed M. What's the latest on Medicare drug price negotiations? Kaiser Family Foundation July 23, 2019. Available at:

https://www.kff.org/medicare/issue-brief/whats-the-latest-on-medicare-drug-pricenegotiations/ (accessed 9/21/19). 